\title{
At last, a chance for postdocs to learn how to teach
}

\author{
Gordon Uno: \\ The struggle is whether \\ you have the 'luxury' of \\ having a teaching postdoc \\ or someone who might be \\ focusing more on research.
}

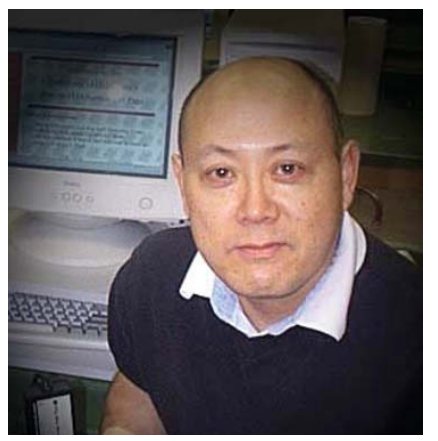

Arizona and the University of California, Davis spend part of their time teaching at institutions whose students are mainly members of ethnic minorities. Salaries, starting at $\$ 28,260$, are based on $\mathrm{NIH}$ standards (see Naturejobs 5; 10 January 2002).

Each grant emphasizes different ways to gain teaching experience. For example, the Davis-San Francisco State University (SFSU) programme, Professors of the Future (PROF), requires research collaboration between faculty mentors at SFSU and Davis. The postdocs are coached in teaching, they co-teach with their SFSU mentor and finally take a course alone. "Teaching is part of what they're here for and it's not an extracurricular activity," says Jerry Hedrick, professor of biochemistry at Davis and programme director for the Davis-SFSU partnership.

\section{CHEMISTRY ESTABLISHED}

Another established programme is the Scholar/Fellow Program for Undergraduate Institutions, set up in 1987 and supported by the Camille and Henry Dreyfus Foundation. So far, 200 fellows have completed the programme of teaching and research in chemistry, chemical engineering and biochemistry departments at undergraduate institutions. Salaries start at a competitive $\$ 35,000$.

Patricia Reggio, professor of chemistry and biochemistry at Kennesaw State University, Georgia, has just received her first Scholar/Fellow award. She hired a postdoc to work on computational modelling of drug-receptor interactions, teach a lecture course in general chemistry and develop a senior-level course in computational chemistry. "The idea is for the facultyaward recipient to mentor the postdoc," says Reggio.

Brian Coppola, an associate professor of chemistry at the University of Michigan in Ann Arbor, has also sponsored several teaching postdocs in the past. Now the University of Michigan has started a teaching postdoc programme similar to the Davis-SFSU arrangement with Oberlin and Kalamazoo colleges.

Postdocs who can teach are a move in the right direction for future faculty, says Coppola, "so they don't walk into the first day of their professional career as unprepared as has been historically true".

Karen Kreeger is a freelance science writer based in Philadelphia.
Web links

Camille and Henry Dreyfus Foundation www.dreyfus.org National Institute for General Medical Sciences www.nigms.nih.gov PROF gradstudies.ucdavis. edu/postdocs/jhpost. htm postdocs at four universities — Emory, North Carolina, 